Check for updates

Kathmandu, Nepal

marty@martylogan.net

Cite this as: $B M J 2021 ; 375: n 2722$

http://dx.doi.org/10.1136/bmj.n2722

Published: 12 November 2021
SOUTH ASIAN HEALTHCARE

\section{Persecution and a pandemic: delivering maternal healthcare to the Rohingya}

\section{The struggle to provide better healthcare for the Rohingya has been unwavering in the face of natural disasters and the pandemic, writes Marty Logan}

Marty Logan freelance journalist

In July, days of torrential rain triggered 320 landslides in the Bangladeshi camps that house almost 900000 Rohingya refugees. The mudslides killed 19 people and damaged or destroyed over 3000 of the shelters in which the refugees live. ${ }^{1}$ For community health workers in these camps, such treacherous conditions are only too familiar.

In April, a report prepared for the United Nations by BRAC University in Dhaka quoted the supervisor of a transport service set up to help pregnant Rohingya women and new mothers access healthcare, ${ }^{2}$ "When we go to rescue a mother, it is a dangerous situation to bring her on a stretcher because someone's foot can slip. Sometimes, the wheels of (the) ambulance get stuck into the mud. It happens every day."

The Muslim Rohingya have been coming to the area of southern Bangladesh called Cox's Bazar since $1978,{ }^{3}$ fleeing persecution in neighbouring Myanmar, which has a Buddhist majority. In 2017, more than 700 ooo arrived, and today the area houses 34 camps carved out of hilly terrain on the south east coast. However, the Rohingya are not recognised as refugees by the government of Bangladesh.

Within the refugee camps, 90 health posts, 41 primary healthcare centres, 23 specialised facilities, and three field hospitals are operating. ${ }^{4}$ Most are run by local or international non-governmental organisations that partner with specialised UN agencies. Over the past few decades, providing adequate healthcare to the Rohingya has been a major undertaking, not least since the onset of the pandemic. ${ }^{5}$

\section{Delivering care}

One of the biggest health challenges has been maternal health-traditional practices restrict women from leaving their homes, transport services in the camps are inconsistent, "roads" are often little more than paths, long distances can discourage walking on uneven terrain, and earthen tracks can quickly turn to mud when it rains.

Malabika Sarker, of the James P Grant School of Public Health at BRAC University, says transport is "one of the 'most neglected' issues. Something as simple as the availability of transportation can make such a contribution to the timely delivery of care," she told The BMJ.

"We invest so much in health facilities and in delivering community care but there is very little infrastructure investment to bring women to facilities."

In January 2019, the United Nations Population Fund (UNFPA) and its partners established a system of referral hubs in eight of the camps to provide transport to health facilities for maternal health emergencies. During the covid-19 pandemic, the operation expanded to include four shuttle buses, which could also be used to access routine maternal healthcare, and both services operate on-call, round the clock, seven days a week.

UNFPA says that the numbers of women benefiting from emergency referral of obstetric cases through the referral hub have consistently increased, even during the pandemic.

The transport service-along with efforts by community health workers to engage refugees, community awareness sessions on reproductive health, and improved health services in the camps-is one reason why the percentage of births in the health facilities in the camps has risen from $41 \%$ in 2019 to $70 \%$ in 2021, while riskier home births have declined proportionally, the agency says.

\section{Obstacles to obstetrics}

A UNFPA report, published in August, emphasised how elements in the traditional Rohingya community can deter women from using health facilities.

Pregnant women "only visit or seek healthcare at the facilities when the case cannot be managed by a traditional birth attendant (who are Rohingya women)," the authors wrote. "This leads to a large number of cases ending up in basic emergency obstetric and newborn care facilities with complications such as prolonged labour, retained placenta, postpartum haemorrhages ... Most (70\%) of the facility based maternal deaths resulted as consequences of home trial followed by prolonged labour landing up in facilities." 6

According to David Kizito, medical coordinator for Médecins Sans Frontières (MSF) in the camps, "the women cannot make decisions themselves; they need someone-it can be the husband or imam ... they are the ones who make the final decision to send a pregnant woman to a facility."

In a November 2020 report by Sarker, ${ }^{2}$ a midwife described how family members influence women's decisions to visit health facilities. "The mothers-in-law and the grandmothers during their 
time used to deliver babies at home," the midwife said. "They would have delivery of 12-17 children at home. Maybe out of those, seven would die, and 10 would survive. They would reason that as Allah did not want, so those seven died.

"That is why we feel a lot of pressure and have to put in a lot of effort to convince them [to go to a healthcare facility]. If the mother-in-law agrees, you would see that the grandmother denies. Or the husband doesn't agree. After counselling all of them, finally, they let the mother go."

Sarker has recommended getting religious and other community leaders on board to persuade families that pregnant women and new mothers need to visit health facilities. She also recommended deploying female health workers to accompany women from referral hubs to health facilities and providing incentives, such as training or sometimes payment, to traditional birth attendants to refer clients to health facilities.

MSF has sent volunteer community health workers to meet with local leaders to try to convince them that births should not happen at home. They've also tried to improve privacy and confidentiality within health facilities. This includes separating delivery beds with curtains, barring unauthorised persons from delivery rooms, and allowing traditional birth attendants who accompany women to the facility to be present during delivery.

The changes are part of an emphasis on "respectful maternity care," says Kizito. This also entails being aware of "the way we welcome the woman who arrives in labour: how do we talk to her, how the midwife has to deal with her, for example, if she has strong contractions; if I need her collaboration, which kind of language style do I have to use and which kind of bad practice do I have to avoid so the woman feels comfortable delivering in the facility."

These steps have had a positive impact: home births accounted for $28 \%$ of deliveries in the first six months of 2020 but just $16 \%$ for the same period in 2021, says Kizito.

\section{What it's like to be a refugee during covid-19}

The pandemic has undoubtedly made things worse, with the Bangladeshi government wary of the risk of a huge cluster outbreak of covid-19 in the overcrowded Cox's Bazar.

In March, MSF wrote on its website of "a sharp deterioration in living conditions in the refugee camps over the past 12 months. The presence of police and the military has increased. At the same time, armed groups have expanded their power base in the camps. As a result, we are hearing about more kidnappings, violence, and extortion.”

MSF said that because of pandemic restrictions put in place by the government, in 2020 services inside the camps were reduced to the bare essentials, and some organisations had to stop working in the camps altogether. "In the early months, our teams had limited access, which led to a reduction in the quantity and range of health services we were able to provide to the Rohingya people," they wrote. ${ }^{7}$

As of 26 September, 32 refugees had died of covid-19 and 3084 cases had been confirmed in the camps, according to the World Health Organization. By mid-September, 33386 refugees aged 55 years and above had received a second dose of covid-19 vaccine, equivalent to $90 \%$ of those who received the first dose. 4

Funding was already running low at the start of last year, but it declined further after the pandemic arrived. As of 16 October, only $48 \%$ of funds requested by the UN to run the operation in the
Rohingya camps in 2021 had been received, and only $57 \%$ of these funds were received by the end of 2020 . Just $\$ 25.4 \mathrm{~m}$ of the $\$ 135 \mathrm{~m}$ $(19 \%)$ required for healthcare in the camps has been received, ${ }^{8}$ while before the pandemic overall funding reached $76 \%$ of the amount requested in 2019, $69 \%$ in 2018 , and $73 \%$ in $2017 .{ }^{9}$

Kizito says his main concern is that, because of funding shortfalls, only a small number of health facilities in the camps are providing a round-the-clock service. "We would like... donors to be able to support some of the partners to run the services $24 / 7$ because when we have permanent services it builds the population's trust, but if during the night and weekend everything is closed, the consequence of this lack of services is (1) an increase in home [births] or (2) late arrival to a referral facility or our hospital."

Funding and covid-19 are just two of the many problems they are facing, says Sarker. Others include exceedingly complex supply chains-because supplies in the UN led operation must be sourced internationally-and declining security. On 22 October, six people were killed and up to a dozen critically injured in a gunfight between two gangs in a camp. ${ }^{10}$ In September, a high profile Rohingya leader was shot dead outside his office.

"I think what is important here now is resource maximisation," Sarker says, "because definitely the money is drying up. Also, the uncertainty caused by other social problems is now interfering with service delivery. We need to invest to create a stable environment. Government needs to have a short term, medium term, and long term plan.”

Competing interests: I have read and understood the BMJ Group policy on declaration of interests and have no relevant interests to declare.

Provenance and peer review: Commissioned; not externally peer reviewed.

Norwegian Refugee Council. How we're responding to floods in Cox's Bazar. https://www.nrc.no/perspectives/2021/how-were-responding-to-monsoon-floods-in-coxs-baza United Nations Population Fund. Fidelity, barriers and facilitators to implementation of referral hub and shuttle service on the utilization of sexual and reproductive health services in Rohingya refugee population: an implementation research. 2021. https://bangladesh.unfpa.org/en/publications/fidelity-barriers-and-facilitators-implementation-referral-hub-and-shuttle-service

32021 Joint response plan. Rohingya humanitarian crisis. January-December 2021. Bangladesh. https://www.humanitarianresponse.info/sites/www.humanitarianresponse.info/files/documents/files/2021_irp_with_annexes.pdf

$4 \quad$ World Health Organization. Rohingya crisis situation report \#19. 3 Oct 2021. https://cdn.who.int/media/docs/default-source/searo/bangladesh/bangladesh---rohingya-crisis--pdf-reports/sitreps/2021/who-cox-s-bazar-situation-report-19.pdf?sfvrsn=8ee2bd5f_7. Vince G. The world's largest refugee camp prepares for covid-19. BM/2020;368:m1205. doi: 10.1136/bmj.m1205 pmid: 32217520

6 United Nations Population Fund. Annual report 2020 on maternal and perinatal mortality surveillance and response (MPMSR) in Rohingya refugee camps in Cox's Bazar, Bangladesh.2021. https://bangladesh.unfpa.org/en/publications/annual-report-2020-maternal-and-perinatal-mor tality-surveillance-and-response-mpmsr

7 Médecins Sans Frontières. As camp conditions deteriorate, Rohingya refugees in Bangladesh face a terrible dilemma. 18 Mar 2021. https://www.doctorswithoutborders.org/what-we-do/newsstories/news/camp-conditions-deteriorate-rohingya-refugees-bangladesh-face-terrible

8 Inter Sector Coordination Group. Rohingya humanitarian crisis. Joint response plan 2021 funding update. 16 Oct 2021. https://www.humanitarianresponse.info/sites/www.humanitarianresponse.info/files/documents/files/2021_10_16_funding_updates_jirp_2021.pdf.

9 Inter Sector Coordination Group. Joint response plan implementation update. Rohingya humanitarian crisis. June-July 2021. https://www.humanitarianresponse.info/sites/www.humanitarianresponse.info/files/documents/files/jrp_implementation_update_june_july_2021.pdf.

10 Aziz A. Rohingya camp attack: slain victim's family starts case, 10 arrested. Dhaka Tribune 2021 Oct 21. https://www.dhakatribune.com/bangladesh/rohingya-crisis/2021/10/24/rohingya-campattack-slain-victim-s-family-starts-case 